\title{
HOW DO THEY BEHAVE ON THE WEB? AN EXPLORATORY STUDY OF MINING THE WEB FOR ANALYTICAL CUSTOMER RELATIONSHIP MANAGEMENT
}

\author{
Myriam Ertz \\ ESG UQAM \\ 405, Rue Sainte-Catherine Est, Montreal, (QC) H2L 2C4 \\ ertz.myriam@uqam.ca \\ Raoul Graf \\ ESG UQAM \\ 405, Rue Sainte-Catherine Est, Montreal, (QC) H2L 2C4 \\ graf.raoul@uqam.ca
}

\begin{abstract}
Web Mining (WM) remains a relatively unknown technology. However, if used appropriately, it can be of great value to the identification of existing customers' behaviours online. The recent technical advances in the field of WM enhance tremendously the analytical Customer Relationship Management (aCRM), still usually related to a simple transactional function. This study follows an exploratory approach to assess whether WM fulfills, alone, all three objectives of the second theme of Xu and Walton's ${ }^{1}$ adapted aCRM framework for customer knowledge acquisition, namely the identification of existing web customers' behaviour. It also investigates to what extent WM should be used in conjunction with traditional marketing research to optimize CRM, and hence marketing, in a web context. In-depth, semi-structured interviews reveal that WM is very well suited to understand existing web customers' transactional web behaviour(s) (i.e. navigation patterns; amount of purchases by week, month, and region; and cross-selling and up-selling opportunities). Nevertheless, WM does not do well in understanding less obvious, underlying dimensions of customer behaviour, including how existing customers develop satisfaction, loyalty, defection and attachment on the web. WM still needs to be complemented with traditional marketing research in order to reach these more difficult but essential aCRM objectives.
\end{abstract}


Keywords: Web Mining, Knowledge Management, Customer Relationship Management, Web Data, Consumer Behavior, Data Mining, Marketing, E-Commerce

\section{INTRODUCTION}

The recent advances in Knowledge Discovery in Databases (KDD), Machine Learning (ML) and Artificial Intelligence (AI) revolve around the tremendous potential offered by more sophisticated Data-Mining (DM) tools. With the explosion of web data, DM has been increasingly applied to analyze these massive web data, a practice known as Web-Mining (WM).

Similar to DM, WM projects yield meaningful information and knowledge only if they are well implemented ${ }^{2}$. In a relational marketing perspective, an interesting application of WM is CRM. End users on the Web are generally not exposed to CRM systems such as dimensional modeling systems (Marketing Information Systems, Data Warehouses, Point-Of-Sale Systems) ${ }^{3}$. CRM systems therefore fail to grasp the ever-growing and dynamic web data. Internet data, however, might uncover valuable knowledge for the company regarding its customers, competitors or prospects. Sometimes, CRM also includes survey or field studies data, which have the disadvantage of being based on customers' perceptions and are inherently subjective, incur various sources of error, and suffer from diverse biases. WM has the advantage of capitalizing on the vast array of data emanating from online settings while being relatively more objective than marketing research outputs because web data reflects factual observations and are thus relatively more objective in nature. Also, web data is not limited to a given and usually pre-selected sample, but reflects a much larger pool of users. Any type of web data referring to any individual can be used.

The issue at hand is it remains unclear to what extent and how WM may fit into a CRM system. Ideally, given its powerful observational, objective and pervasive characteristics, WM is a much better candidate for CRM instead of costly surveys or experiments, especially to discover web customers' online behaviors. This paper investigates to what extent WM methods applied to web data fulfill the three aCRM objectives adapted from $\mathrm{Xu}$ and Walton's ${ }^{1}$ typology of aCRM objectives in offline settings. More specifically, these objectives relate to discovering the behaviors of existing web customers online.

The first research question relates to the identification of existing web customers' online behaviors. The second research question investigates to 
what extent WM methods applied to web data capture how existing web customers develop satisfaction and loyalty on the internet? Consequently, since loyalty is explored, it also seems interesting to uncover possible WM applications regarding defection. Hence, the third research question deals with the extent to which WM methods identify how existing web customers remain attached to or defect from a given business on the internet.

\section{BACKGROUND LITERATURE}

\subsection{Web-Mining (WM)}

WM refers to techniques that are used to automatically discover and extract information from web documents and services ${ }^{4,5,6}$. It refines large, complete, reliable and cheap data in a time-effective manner ${ }^{2}$. It is thus a technology that is suitable for analytical tasks on large data sets, especially in Customer Relationship Management (CRM) ${ }^{7}$.

WM suffers some limitations though. It usually requires costly website reconfigurations due to ill-structured designs ${ }^{2}$. WM does not ultimately guarantee the discovery of relevant patterns in the data and whenever data quality is bad the whole WM process is void ${ }^{8}$. Also, only a small proportion of the information on the web is relevant and useful ${ }^{9}$, thus it is a huge job to sift through the data involved with WM. It is time-consuming and may not yield expected returns. Moreover, it is difficult to identify unique users since two users can use the same computer, browser, IP address, or even sets of web pages, making it hard to analyze the behavior of a single user ${ }^{2}$. WM entails a whole set of normative issues relating to the protection of privacy and individuality ${ }^{10}$ As a result WM is not self-sufficient, it will always require experts who can develop and implement WM projects as well as translate and leverage WM outputs into managerial terms.

On the other hand, WM capitalizes on the vast amount of readily available web data, overcomes traditional market research limitations, and enables 1-to-1 granular marketing, thus mass customization ${ }^{3}$. Despite its limitations, WM may overcome the behavior identification and hyper-segmentation challenges of today's marketplace. If appropriately disseminated throughout the organizational layers of a business in a real-time fashion, WM may be a valuable part of an integrated Marketing Information Systems (MIS), acting as a powerful tactic and strategic decision-making platform ${ }^{11}$. In this way, the knowledge that WM produces is optimally disseminated and used throughout relevant organizational units. The most common form of such MIS systems in marketing, namely CRM, and more specifically its analytical applet (aCRM), is introduced in the next section. 


\subsection{Analytical Customer Relationship Management (aCRM)}

Wahlberg et al. ${ }^{12}$ conceptualized CRM as being a matter of technology-enabled customer information management activities that includes an analytical applet ${ }^{1,13,14,15}$. aCRM refers to the usage of DM tools in order to generate customer profiles, identify behavior patterns, determine satisfaction levels, and support customer segmentation to develop appropriate marketing and promotion strategies ${ }^{1}$. The offline-based aCRM process encompasses DM, forecasting, and scoring ${ }^{3}$ to segment customers more effectively or optimize offerings to better fit customers' buying profiles $^{1}$.

$\mathrm{WM}$ is a good fit for this analytical applet since it explores existing web customers' behaviors. Online web data (e.g. hyperlinks, web logs, etc.) complements offline data by providing information on customers and prospects from additional channels, including, first and foremost, from the internet. Adding web data to aCRM is thus expected to optimize that process since it will leverage more holistic and powerful marketing capacities that may also be used in offline settings.

\section{RESEARCH QUESTIONS AND METHODOLOGY}

\subsection{Research Questions and Propositions}

$\mathrm{Xu}$ and Walton ${ }^{1}$ developed a typology of aCRM objectives for a customer knowledge acquisition framework. However, this framework refers to an offline-based aCRM process. By adapting $\mathrm{Xu}$ and Walton's ${ }^{1}$ framework to the web context, it is possible to develop a specific framework of aCRM for knowledge acquisition of web users' behavior (see Figure 1). The set of objectives related to the discovery of existing customers' behavior is located in the upper-right, red-dotted quadrant. The purpose of this study is thus to explore the use of WM to fulfill web-adapted aCRM objectives related to the identification of existing web customers' behavior.

To fulfill the 3 main objectives related to the identification of existing web customers' behaviors, WM offers four major methods and their respective techniques: clustering, classification, prediction, and association analysis. Additional methods exist, but for conciseness and focal purposes, this study does not include them and emphasizes the core ones instead. More specific studies would also have been difficult to discuss with respondents because some of them might not be familiar with WM methods, making comparisons between answers more difficult.

WM input can comprise a great variety of data types, however this study focuses on the most widespread and convenient data type for analytical purposes, namely browsing behavior data. As for WM techniques, 
another reason for not handling more data types is not knowing to what level respondents are familiar with various existing data types. As a cautious principle, we preferred to adopt a more conservative approach by limiting the data types to the most common ones, thus ensuring that all respondents can respond and enabling valid comparisons between answers.

\begin{tabular}{|c|c|c|}
\hline -Segmenting web customers & $\begin{array}{l}\text { Internal } \\
\text { (existing) }\end{array}$ & \multirow{3}{*}{$\begin{array}{l}\text {-Identifying web customers } \\
\text { behaviour patterns } \\
\text {-Identifying web customers' } \\
\text { satisfaction and loyalty } \\
\text { patterns } \\
\text {-Identifying web customers' } \\
\text { retention and defection } \\
\text { patterns }\end{array}$} \\
\hline $\begin{array}{l}\text {-Identifying web customers' } \\
\text { loyalty and defection } \\
\text { statuses }\end{array}$ & & \\
\hline $\begin{array}{l}\text {-Identifying strategically } \\
\text { important web customers }\end{array}$ & & \\
\hline $\begin{array}{l}\text { Who } \\
\text { (profiling) }\end{array}$ & & $\begin{array}{l}\text { How } \\
\text { (pattern) }\end{array}$ \\
\hline $\begin{array}{l}\text {-Segmenting web } \\
\text { prospects }\end{array}$ & & $\begin{array}{l}\text { - Identifying web prospects' } \\
\text { behaviour patterns }\end{array}$ \\
\hline $\begin{array}{l}\text {-A cquiring new } \\
\text { web customers }\end{array}$ & & $\begin{array}{l}\text { - Identifying web } \\
\text { prospects' defecting } \\
\text { patterns to and from }\end{array}$ \\
\hline & $\begin{array}{c}\text { External } \\
\text { (prospect) }\end{array}$ & loyalty patterns to them \\
\hline
\end{tabular}

Figure 1. aCRM for knowledge acquisition of web users' behavior patterns

WM methods provide scores that enrich databases since they are integrated with databases ${ }^{16}$. Clustering techniques and association analysis typically provide clusters of customers who share similar behaviors, which may be used to reorganize the website according to discovered clusters, association rules, or Bayesian models. These models enrich the database by integrating the code of the cluster in the customer database or by integrating the model directly on the website ${ }^{15}$.

Classification and prediction methods also provide scores that enrich the database since they are integrated with the database ${ }^{16}$. Together with clustering, these techniques provide models that are useful to develop recommendation modules (i.e. intelligent agents, recommendation systems, and collaborative filtering-based recommendations) ${ }^{10}$. Hence, in order to investigate to what extent WM methods applied to web data identify existing web customers' behavior on the web, the research propositions are as follows: 
RP1a: Web data generated by existing web customers highlight the particular behavior patterns of existing web customers when they are navigating the internet.

RP1b: WM methods applied to web data provide descriptive and predictive modeling of web customers' behavior on the internet.

It costs roughly five times more to attract a new customer than to retain an existing one ${ }^{17}$. Ensuring customer loyalty is thus a sound business strategy. WM methods, particularly prediction and classification, provide scores (scoring) relating to the loyalty patterns of web customers and may be used to make future predictions as to customers' future loyalty status. In order to determine to what extent WM methods applied to web data capture how existing web customers develop satisfaction and loyalty on the internet, the research propositions are as follows:

RP2a: Web data generated by existing web customers' describe their existing satisfaction and loyalty patterns on the internet.

RP2b: WM methods applied to web data grasp the dynamics of existing web customers' satisfaction and loyalty development patterns on the internet.

It is also important for businesses to understand how current customers become attached to an e-business in order to benefit from the "power of extension" generated by attached customers ${ }^{18}$. WM enables scoring and forecasting as well as sequential tracking of browsing and searching patterns. Consequently, in order to find out to what extent WM methods identify how existing web customers remain attached to or defect from a given business on the internet, the research propositions are as follows:

RP3a: Web data generated by existing web customers describe existing web customers' attachment and defection patterns on the internet.

RP3b: WM methods applied to web data capture the dynamics of existing web customers' attachment and defection patterns on the internet.

\subsection{Methodology}

WM is widely discussed in IT and computer science literature. However, few articles or white papers on the subject exist in business literature. The lack of relevant scientific sources on the application of WM to the marketing context ${ }^{19}$, called for an exploratory research design. The main goal of the research was to explore and discover WM experts' opinions about current WM potential regarding identification of existing web customers' behaviors on the web.

A survey was developed based on the research questions to be answered and research propositions to be explored. Questions were 
exclusively in an open-ended format and asked respondents their opinions on the capabilities of WM to fulfill the three main objectives of aCRM to identify existing web customers' behaviors. One question referred to each objective. Prior to the survey, an introduction provided respondents with the context, aims, and expected outcomes of the study as well as an outline of the interview. In addition, a short lexicon defined the different WM methods under scrutiny, in order to avoid misinterpretations.

A convenient sample was drawn, and the researcher was able to conduct a dozen valid, in-depth, semi-structured interviews. The number could not be higher since only those respondents who had a thorough knowledge of WM and also a sound understanding of business and marketing issues, which is a rather rare profile, qualified for the interview. About half of the respondents were senior directors or c-level executives in public or private organizations, while the other half consisted of academicians. Their areas of expertise ranged from marketing, communication, or IT through engineering and $\mathrm{R} \& \mathrm{D}$, but all had previously been involved in a WM project in an academic or professional context. The majority of the respondents were aged 36 to 55 years, and one respondent was more than 55 years old. Most were from Canada, one from Belgium, and two from the United States. The sample was thus heterogeneous enough to allow for a diversity of opinions and responses.

Most in-depth interviews were conducted face-to-face and lasted between one and two hours. Answers were completely transcribed and summarized into a response matrix. Each respondent was assigned to one column and his/her answers were summarized under the three main themes (questions), in rows. A content analysis led to the production of a synthesis of all answers to validate or invalidate research propositions and, ultimately, research questions.

\section{RESULTS}

\subsection{Identification of Existing Web Customers' Behaviors on a Website}

Most respondents agreed that data quality is of utmost importance for the WM process. Internal and external web data should be converging, large, sufficiently homogeneous, granular, as well as properly extracted and, ideally, issued by logged in web users. Among WM tools, it appears that the more automated techniques tend to be faster, easier to use and offer real-time insight into existing web customers' behavioral patterns. Automated processing in real-time is preferred to the more traditional model building and deployment approach. Consequently, descriptive methods should be used to get an initial feeling of behaviors. WM provides a more 
sophisticated explanation of behavior such as sequential patterns. RP1a is thus validated.

However, WM is not self-sufficient to detect existing web customers' behavior on so-called psychologically related dimensions such as perception, perception of self, motivation, personality or lifestyle. Most respondents argued that behavior in a web context refers strictly to browsing and purchasing behavior. The broader "customer behavior" and its underlying dimensions cannot be studied per se by WM, which invalidates RP1b. Traditional surveys should be used as complements to these tools, in a triangulation perspective, to grasp customers' cognitive, affective, and conative dimensions. In answer to RQ1, WM methods partially enable the identification of existing web customers' behavior on the internet.

As shown in Figure 2, the input web data should ideally be converging, large, homogeneous enough, as well as properly extracted and ideally resulting from customers who $\log$ in. This will enable web managers to anticipate specific offers for each different customer, enhance the web environment according to each unique web user through customization, or even measure the effects of a web marketing campaign.

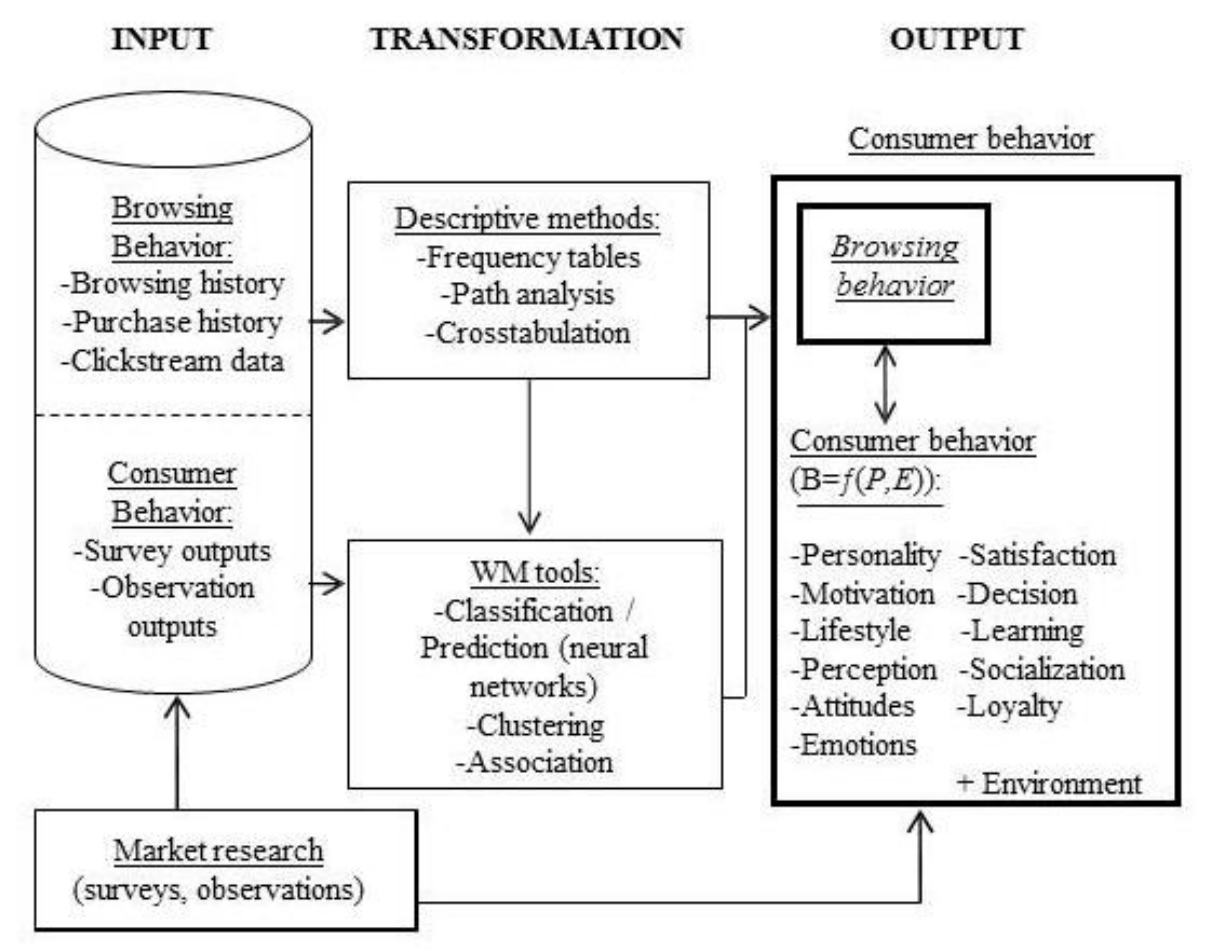

Figure 2. WM-enabled identification of existing web customers' behaviours 


\subsection{Identification of Existing Web Customers' Satisfaction and Loyalty Development Patterns on a Website}

Satisfaction is a complex construct, with hidden and underlying facets that may be hard to measure on the internet, requiring instead market research in the form of surveys, as discussed previously. However, respondents argued that for satisfaction and loyalty constructs, specifically, there is useful data to exploit, such as web browsing behavior (e.g. intensity of usage, historical usage data) and profile data (e.g. filling in of online forms, posts). One respondent added that these data are less directional if respondents are required to $\log$ in. This partially validates RP2a.

This data may then be useful input to identify the paths of loyalty development by using both WM and descriptive tools. In fact, respondents indicated that, although not very useful to tackling the satisfaction development process, WM and descriptive statistics do help gauge the efficiency of a planned customer loyalty marketing program, at least if a deliberate loyalty strategy was deployed at all. This, in turn, enables the business to drive powerful viral marketing. If no specific loyalty marketing effort was engaged, WM is still useful to determine loyalty development based on the e-business' own loyalty development criteria. RP2b is thus also partially validated, as is RQ2. Hence, in answer to RQ2, WM methods applied to web data partially capture how existing web customers develop satisfaction and loyalty on the internet.

As shown in figure 3, which is a summary of the respondents' answers, company-specific attributes, such as order of entry in the industry/sector, value proposition, product attributes, user experience, or level of entertainment, directly influence the customer-specific attributes relating to emotions, attitude, and loyalty toward the website. Customer attributes may not be grasped per se unless market research in the form of surveys is conducted among web users. Meanwhile, the web data does partially reflect those elements through web browsing behavior (e.g. intensity of usage, historical usage data) and profile data (e.g. filling in of online forms, posts), which are more accurate and less directional if customers are required to log in.

\subsection{Identification of Existing Web Customers' Attachment and Defection Patterns on a Website}

One respondent stated that systems are not conceived to understand how, and even less why, customers leave. In fact, such knowledge can be obtained only from intensive data aggregation and analysis to get a converging image through triangulation and inferences based on analytical outputs. The input data has to be rich and diversified enough (search 
keywords, user experience data, transactional data, communications interactions, browsing behavior, visits information, etc.), which partially validates RP3a.

\section{INPUT TRANSFORMATION OUTPUT}

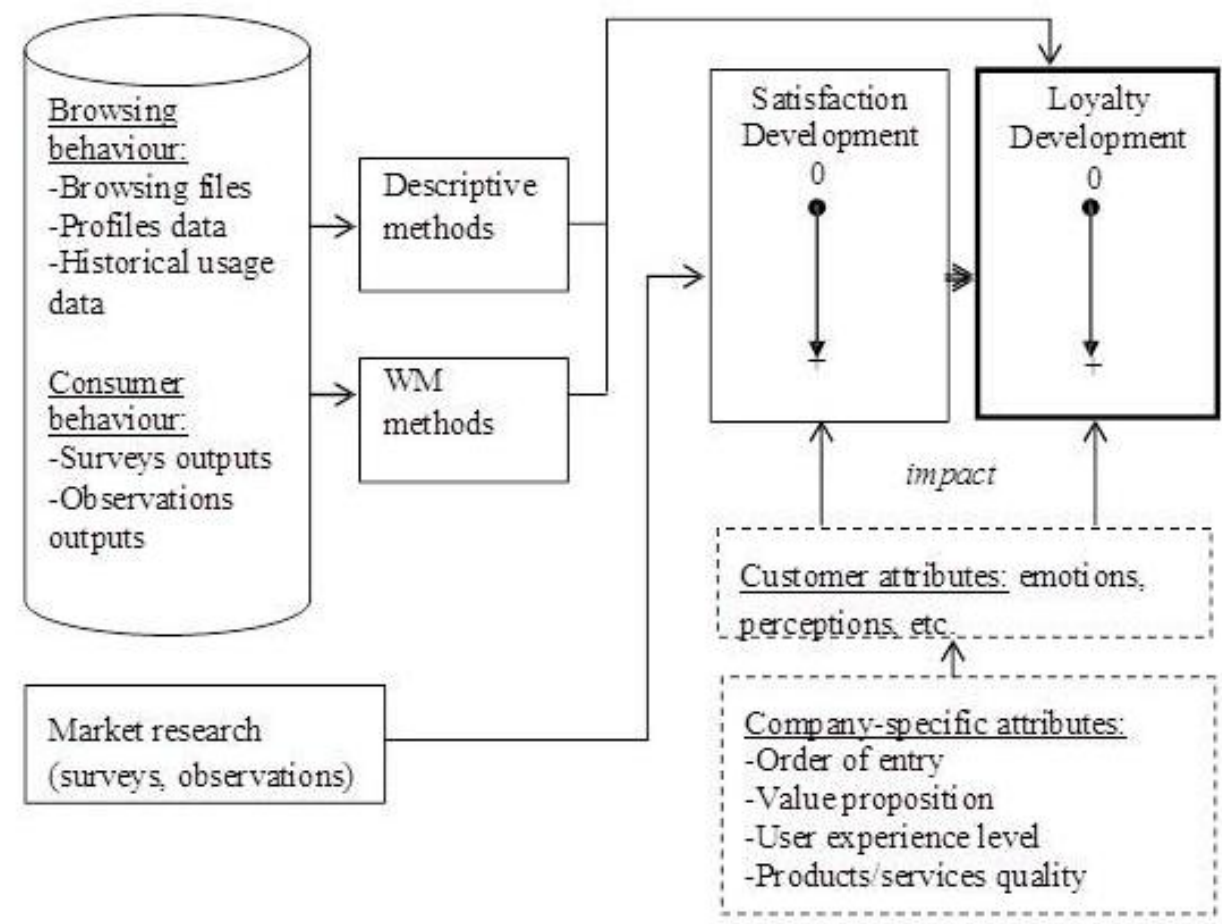

Figure 3. WM-enabled identification of existing customers' loyalty development patterns

WM tools are then appropriate to determine only transactional loyalty patterns, that is, how existing web customers develop attachment or defection in terms of continuous purchases, visits, or desired transactions. If actions are ongoing, customers are deemed attached, and if actions stop, customers are deemed defected. The emotional and affective aspects of loyalty cannot be grasped with WM tools alone. Market research needs to complement WM to provide additional insight into transactional patronage and determine emotional patronage, hence providing an actual patronage view encompassing the nuances of observed transactional patronizing. Contingent variables that influence attachment or defection (such as cash availability of the respondent, seasonality, and special occasions) and their effects on loyalty can also be better grasped through market research. RP3b 
is thus partially validated. Consequently, in answer to RQ3, WM methods only partially enable identification of how existing web customers remain attached to or defect from a website.

As displayed in Figure 4, the input data has to be rich and sufficiently diversified. WM tools are then appropriate to determine only transactional loyalty patterns, specifically how existing web customers develop attachment or defection in terms of continuous purchases, visits, or desired transactions. If actions are ongoing, customers are deemed attached, and if actions stop, customers are deemed defected.

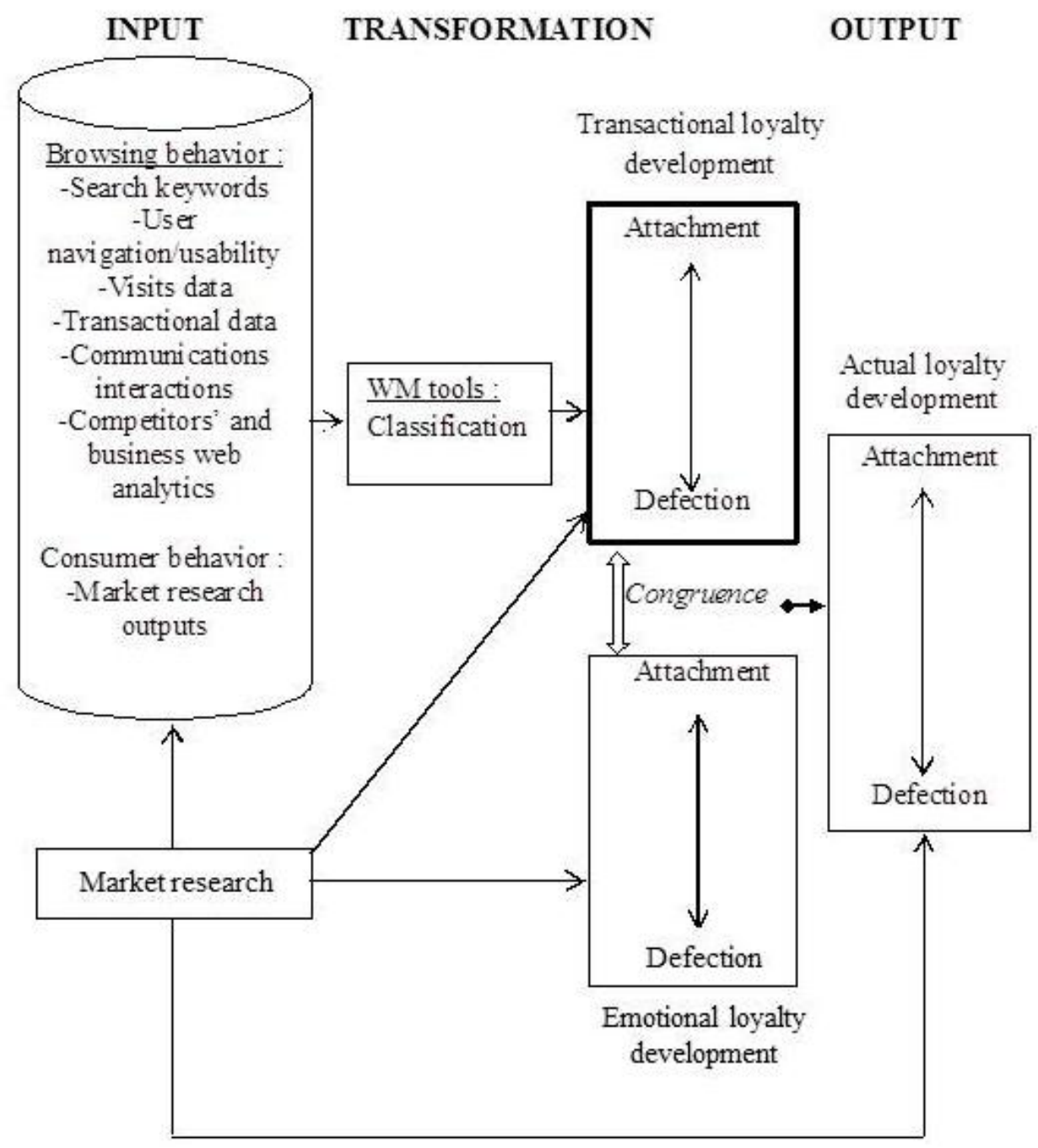

Figure 4. WM-enabled identification of existing web customers' attachment or defection patterns. 


\subsection{Discussion of the Results}

In a knowledge-enabled CRM framework, WM offers limited but insightful information on existing web customers' behaviors. Input data used in the WM project should have several key characteristics (e.g. large, granular, etc.) and may be: (1) internal, e.g., search keywords, communications interactions, web analytics, browsing history, profiles, transactional, data and clickstream data; or (2) external, e.g., competitors' web analytics or 3rd party data. Previous or current market research data resulting from surveys or observations can also be integrated into the WM process provided they are of acceptable quality and conform to the WM pre-processing specifications.

Descriptive statistics are particularly useful in identifying customers' behaviors in a less complex fashion than do WM tools. They may also be used as exploratory tools to have a first impression of the data that will be further processed with WM tools. The concept of behavior actually has two facets in a web context: (1) the browsing behavior facet and (2) the consumer behavior facet. The former refers to the actual, objective, observable, and factual actions of an individual on a website that captures everything she does and that can be recorded in multiple ways for straight analysis. The latter refers to the complex intermingling of all underlying psychological layers that constitute the human being and that are widely studied in a discipline that bears the same name. Behaviour thus encompasses various internal influences, such as personality, motivations, lifestyle, perceptions, attitudes, emotions, satisfaction, loyalty, decision process, learning, socialization, and the concept of self. Customer behavior can be influenced by company-specific attributes such as order of market entry, level of user experience offered, etc. For instance, first-movers (the order of market entry variable) tend to be more appreciated by customers because they are perceived as being pioneers and tend to be more liked by the public than others ${ }^{18,20,21}$.

Both types of behaviors surely influence each other, but it remains unclear to what extent the typical customer behavior displayed in offline contexts, i.e. everywhere but on the internet, differs from the browsing behavior displayed on the internet and even on different types of internet channels. Is it merely transposable or is there such a thing as an e-consumer behavior that an individual switches to when navigating on the internet? In fact, it has often been determined that customers tend to be more liberated on the internet than in real-life, but additional research is needed on the subject. Furthermore, it has been found that while browsing behavior can be identified very accurately by WM tools and, to a lesser extent, by descriptive methods, consumer behavior cannot be that easily determined by 
WM, at least, not yet. Additional market research is still required for that purpose.

The level of congruence between browsing behavior and consumer behavior cannot be specifically determined, nor can the resulting actual satisfaction development be pinpointed through WM alone. Satisfaction is the major antecedent of loyalty, but without knowledge about the satisfaction level of customers, it is difficult to identify customers' loyalty development patterns. Instead, WM enables marketers only to identify how web customers develop transactional loyalty and how they nurture that transactional loyalty on a continuous basis by remaining attached or by defecting. Transactional loyalty, however, tells little about the underlying buying process of the customer or emotional loyalty, which refers to the liking or disliking of a website on a continuous basis by remaining emotionally attached or not. Emotional loyalty development cannot be grasped by means of WM tools. Congruence between transactional and emotional loyalty development mirrors the actual or real loyalty development.

Therefore, the second theme corresponding to the second meta-objective of identifying existing web customers' transactional browsing behaviors on the internet, as identified in $\mathrm{Xu}$ and Walton's ${ }^{1}$ adjusted framework, can be partially fulfilled by using WM. Hence, WM fits well in an aCRM system and provides added value regarding web customers' transactional behavior, which is core to pure players' marketing knowledge requirements and increasingly so for brick-and-click players. Meanwhile, market research remains a cornerstone for identification of the more psychological and psychographic aspects of web customer behavior. Traditional descriptive statistics are also useful complementary tools in that regard.

\section{CONCLUSION}

This study sought to uncover the tremendous potential of WM when integrated into the blended aCRM framework and leverage insightful knowledge about existing web customers who interact with e-commerce portals. The study investigated the benefits of WM in the aCRM applet of the marketing information system when deployed in a relational marketing paradigm. WM is well-suited to track operational and transactional aspects of customers' online behavior, but not underlying reasons, motives, or preferences for which market research is still better suited. WM thus enables partial fulfillment of the fourth objective of aCRM. In fact, it cannot determine the consumer behavior variables of customers with much accuracy, but it can identify their browsing behavior. It follows, then, that 
WM can only partially fulfill the fifth objective, namely identification of satisfaction and loyalty development patterns. Moreover, it can identify only the transactional loyalty development, but not the satisfaction and emotional loyalty development. Unfortunately, it cannot fulfill the sixth objective of aCRM, namely identifying attachment and defection patterns of web customers (i.e. their patronage of a web business).

In light of this study, it is very important for managers and practitioners to understand that WM is not an end unto itself. It is a combination of tools and techniques that enable experienced teams to extract useful meaning from big (un)structured data. Firstly, managers should be aware of the garbage in/garbage out maxim: not all information is necessarily good to process. The analytical CRM side of a business should also be aligned with its strategic side. Such projects should always be conducted in line with organizational mission, vision, objectives and capacity. Second, data produced by logged in customers appear to be the best kind of data since profiles can be precisely attached to a specific customer. Consequently, whenever possible managers should implement secure user access on their websites to recognize and to trace accurately the behaviour of their existing web customers. Third, companies' databases should also allow for high volumes of data entries, since higher quantities of quality data yield better results. Finally, the devil is in the details, for it is mainly through the WM project planning and the quality and availability of the data as well as the robustness of the WM analytical process that most benefits will be derived from WM.

This research is very broadly-defined. It assessed the four major WM methods to determine their effective use for reaching a generic taxonomy of three aCRM objectives as determined by $\mathrm{Xu}$ and Walton ${ }^{1}$. A number of limitations are worth recognizing and should give rise to future research avenues. First, it is not clear to what extent WM enables automatic creation of dynamic models to bypass the thorough slow-and-steady approach. Additional research should estimate to what extent WM methods truly enable automatic model creation, implementation, and deployment directly on the website, without human interaction. Second, it remains unclear to what extent the typical customer's behaviour displayed in the offline context can be transposed online. Additional research could investigate this. Third, the web should be mined for feelings and not for facts ${ }^{22}$. Other studies could determine to what extent sentiment analysis is useful for marketing to automate the processes of sifting through the noise, understanding conversations, predicting future developments, identifying relevant content as well as the most influential opinion holders, and detecting the underlying dimensions of consumer behaviour ${ }^{23}$. Fourth, this study focused on four main WM methods (clustering, classification, prediction, and association 
analysis) as well as browsing behaviour data as input for WM. This may limit the results of this study, and additional research could focus on the further insight that could be obtained from a more diverse mix of methods and input data for the WM process. Evidently, business science, especially marketing, will always be needed in order to leverage that knowledge appropriately and for optimal returns.

\section{REFERENCES}

[1] M. Xu, and J. Walton, Gaining customer knowledge through analytical CRM. Industrial Management and Data Systems, 105(7), p955-971, 2005. http://dx.doi.org/10.1108/02635570510616139.

[2] I. Mihai, Web-Mining in e-commerce. Oradea, Romania: Annals of the University of Oradea, Economic Science Series, 2009.

[3] R. Kimball, and M. Ross, The data warehouse toolkit: The complete guide to dimensional modeling second edition. New York: Wiley, 2002.

[4] R. Cooley, B. Mobasher, and J. Srivastava, Web-Mining: information and pattern discovery on the world wide web. In P. Storms (Ed.), Proceedings of the International Conference on Tools with Artificial Intelligence (p558-567). Newport Beach, CA: IEEE Press, 1997. http://dx.doi.org/10.1109/TAI.1997.632303.

[5] R. Kosala, and H. Blockeel, Web mining research: a survey. SIGKDD Explorations - Newsletter of the ACM Special Interest Group on Knowledge Discovery and Data-Mining, 2(1), p1-15, 2000. http://dx.doi.org/10.1145/360402.360406.

[6] J. Srivastava, R. Cooley, M. Deshpande, and P.N. Tan, Web usage mining: discovery and applications of usage patterns from web data. $\begin{array}{llll}\text { SIGKDD Explorations, } & 1999 .\end{array}$ http://dx.doi.org/10.1145/846183.846188.

[7] N.M. Adams, Perspectives on data-mining. International Journal of Marketing Research, 52(1), p11-19, 2009.

[8] A. Rafea, and S. El-Beltagy, Data mining center of excellence organizational web mining. Cairo, Egypt: First annual technical report TR/COE_WM, 2006.

[9] J. Sivaramakrishnan, and V. Balakrishnan, Web mining functions in an academic search application. Informatica Economica, 13(3), p132-139, 2009.

[10] L. van Wel, and L. Royakkers, Ethical issues in web data mining. Ethics an Information Technology, 6(2), p129-140, 2004. http://dx.doi.org/10.1023/B:ETIN.0000047476.05912.3d.

[11] J. Ranjan, and V. Bhatnagar, Role of knowledge management and analytical CRM in business data mining based framework. The 
Learning Organization, 18(2), p131-148, 2011. http://dx.doi.org/10.1108/09696471111103731.

[12] O. Wahlberg, C. Strandberg, H. Sundberg, and K.W. Sandberg, Trends, topics and under-researched areas in CRM research. International Journal of Public Information Systems, 5(3), p191-208, 2009.

[13] N.C. Romano, and J. Fjermestad, Electronic commerce customer relationship management: an assessment of research. International Journal of Electronic Commerce, 6(2), p61-113, 2002. http://dx.doi.org/10.1080/10864415.2001.11044232.

[14] N.C. Romano, and J. Fjermestad, Electronic commerce customer relationship management: a research agenda. Information Technology and Management, 4(2-3), p233-258, 2003. http://dx.doi.org/10.1023/A:1022906513502.

[15] M. Bazsalicza, and P. Naim, Data mining pourle web: Profiling, filtrage collaboratif, personnalisation client. Paris: Eyrolles, 2001.

[16] Q. Zhang, and R.S. Segall, web mining: A survey of current research, techniques, and software. International Journal of Information Technology and Decision-Making, 7(4), p683-720, 2008. http://dx.doi.org/10.1142/S0219622008003150.

[17] F.R. Miller, and L.E. Miller, That's customer focus!: The overworked and underappreciated manager's guide to creating a customer-focused organization. Booksurge, 2007. Retrieved on June 4, 2012, from http://www.thatscustomerfocus.com/downloads/Excerpt\%20from\%20T hats\%20Customer\%20Focus.pdf.

[18] R.A. Kerin, P.R. Varadarajan, and R.A. Peterson, First-Mover advantage: A synthesis, conceptual framework, and research propositions. Journal of Marketing, 56(4), p33-52, 1992.

[19] N.K. Malhotra, Marketing research: An applied orientation (Sixth Edition). Upper Saddle River, NJ: Prentice-Hall, 2010.

[20] S. Srinivasan, R. Anderson, and P. Kishore, Customer loyalty in E-Commerce: A exploration of its antecedents and consequences. Journal of Retailing, 78(1), P41-50, 1998. http://dx.doi.org/ 10.1016/S0022-4359(01)00065-3.

[21] E. Van Hippel, Generation and evaluation of novel product concepts via analysis of experienced users. Massachusetts: Marketing Science Institute, Cambridge.

[22] A. Wright, Mining the web for feelings, not facts. The New-York Times, August 23, 2009.

[23] B. Mobasher, and O. Nasraoui, Web usage mining. In B. Liu (Ed.), Web data mining: Exploring hyperlinks, contents, and usage data (data-centric systems and applications) (Second edition). Chicago, IL: Springer, 2011. 